\title{
The coming of age of galectins as immunomodulatory agents: impact of these carbohydrate binding proteins in T cell physiology and chronic inflammatory disorders
}

\author{
J M Ilarregui, G A Bianco, M A Toscano, G A Rabinovich
}

Ann Rheum Dis 2005;64:iv96-iv103. doi: 10.1136/ard.2005.044347

Immune cell homoeostasis is attributed to multiple distinct safety valves that are interconnected and intervene at defined checkpoints of the life cycle of immunocytes to guarantee clonal expansion and functional inactivation of self-reactive potentially autoaggressive lymphocytes. Galectins, animal lectins defined by shared consensus amino acid sequence and affinity for $\beta$-galactose containing oligosaccharides, are found on various cells of the immune system, and their expression is associated with the differentiation and activation status of these cells. Over the past few years, galectins have been implicated in the regulation of many aspects of $T$ cell physiology such as cell activation, differentiation, and apoptosis. In addition, a growing body of experimental evidence indicates that galectins may play critical roles in the modulation of chronic inflammatory disorders, autoimmunity, and cancer. Given the increased interest of immunologists in this field, the growing body of information raised during the past few years and the potential use of galectins as novel anti-inflammatory agents or targets for immunosuppressive drugs, we will summarise recent advances on the role of galectins in different aspects of T cell physiology and their impact in the development and/or resolution of chronic inflammatory disorders, autoimmunity, and cancer.

G alectins, a growing family of evolutionarily conserved carbohydrate binding proteins, have recently attracted the attention of immunologists as novel regulators of inflammation and autoimmunity. ${ }^{12}$

\section{GALECTINS AS IMMUNOMODULATORY AGENTS: BIOCHEMISTRY, STRUCTURE, AND SUBCELLULAR LOCALISATION}

Members of the galectin family are defined by a conserved carbohydrate-recognition domain (CRD) with a canonical amino acid sequence and affinity for $\beta$-galactosides. ${ }^{3}$ To date, 15 mammalian galectins have been identified, which can be subdivided into those that have one CRD and those that have two CRDs in tandem. In addition, galectin-3, a oneCRD galectin, is unique in that it contains unusual tandem repeats of short amino acid stretches fused onto the CRD. ${ }^{5}$

Many galectins are either bivalent or multivalent with regard to their carbohydrate binding activities-some oneCRD galectins exist as dimers; two-CRD galectins have two carbohydrate binding sites, and galectin-3 forms oligomers when it binds to multivalent carbohydrates. ${ }^{5}$ In this way, galectins can form ordered arrays of complexes when they bind to multivalent glycoconjugates much like the lattices formed by antibodies and multivalent antigens. ${ }^{6}$ Some galectins are distributed in a wide variety of tissues, whereas others have a more restricted localisation. The expression of galectins is modulated during the activation and differentiation of immune cells and changes under different physiological or pathological conditions. ${ }^{7}$

Galectins are present both inside and outside cells, and function both intracellularly and extracellularly. Although galectins have features of cytosolic proteins, they are secreted by non-classical (non-ER-Golgi) pathways. ${ }^{4}$ Extracellularly, galectins can bind to cell surface glycoconjugates that contain suitable galactose-containing oligosaccharides. As galectins can bind either bivalently or multivalently, they can crosslink cell surface glycoconjugates, which, like many other receptor-ligand systems, can trigger a cascade of transmembrane signalling events. Through this mechanism, galectins can modulate processes that include apoptosis, cytokine secretion, and cell adhesion and migration. ${ }^{7}$ Furthermore, intracellularly galectins are engaged in processes that are essential for basic cellular functions such as pre-mRNA splicing, regulation of cell growth, and cell cycle progression. ${ }^{8}$

\section{GALECTINS IN THE REGULATION OF T CELL PHYSIOLOGY}

Galectins as regulators of T cell survival: influence in the maintenance of central and peripheral $T$ cell tolerance

A dynamic balance in the quantity and activation state of the cells participating in immune responses is essential for achieving appropriate proliferative and effector responses to antigens while avoiding autoimmunity. ${ }^{9}$ Immune cells are subject to cell death checkpoints at many stages during their lifespan to ensure proper development, maintain homoeostasis and prevent disease. Different families of proteins can regulate immune cell death, including death inducing ligands, death receptors, and intracellular regulators of death pathways.

\section{Galectin-1}

A growing body of experimental evidence indicates that galectins may play critical roles in the regulation of immune cell death (reviewed in references 1 and 7) (fig 1). Galectin-1 induces cell growth inhibition and cell cycle control and promotes apoptosis of activated T cells. ${ }^{10-20}$ Galectin- 1 has shown specific growth inhibitory properties towards concanavalin A (Con A) stimulated rat and mouse T cells, ${ }^{19} 20$ phytohaemagglutinin (PHA) activated human T cells ${ }^{10}{ }^{17}$ and

Abbreviations: APC, antigen presenting cell; $\mathrm{CIA}$, collagen-induced arthritis; CRD, carbohydrate recognition domain; EAE, experimental autoimmune encephalomyelitis; EAMG, experimental autoimmune myasthenia gravis; ECM, extracellular matrix; $E R$, endoplasmic reticulum; GVHD, graft versus host disease; IBD, inflammatory bowel disease; IFN, interferon; IL, interleukin; NSN, nephrotoxic serum nephritis; Th, T helper; TNF, tumour necrosis factor 


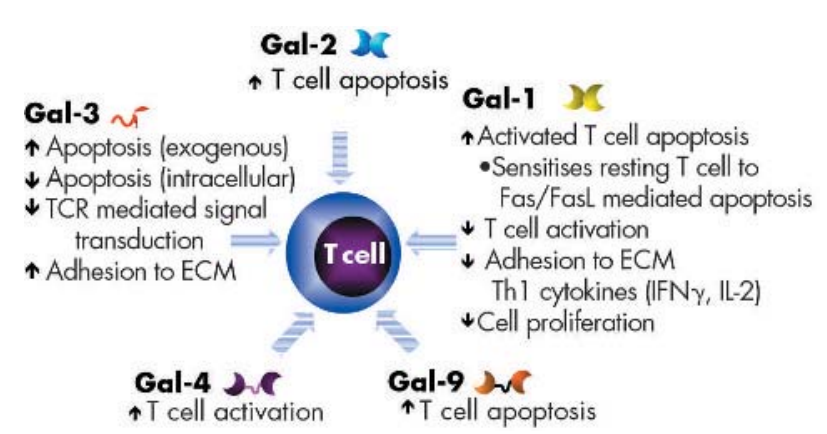

Figure 1 Influence of galectins (Gal) in the regulation of T cell physiology. This scheme illustrates the influence of different members of the galectin family on different T cell functions including T cell apoptosis, activation, adhesion, and cytokine secretion. ECM, extracellular matrix.

human alloreactive T cells. ${ }^{15}$ Furthermore, galectin- 1 induces apoptosis of developing thymocytes and peripheral T lymphocytes. ${ }^{11-20}$

One concern regarding the proapoptotic activity of galectin- 1 is that this effect has been demonstrated in most cases at relatively high concentrations (micromolar range) and it is uncertain whether high levels of soluble protein can be produced in vivo. Interestingly, recent evidence indicates that the amount of galectin-1 secreted by different cell types is sufficient to kill $\mathrm{T}$ cells, when galectin- 1 is presented in the context of extracellular matrix (ECM) glycoproteins. ${ }^{21}$ Moreover, the presence of galectin-1 in activated but not resting $\mathrm{T}$ cells ${ }^{10} 22$ suggests a potential autocrine suicide mechanism to achieve homoeostasis during the termination of an immune response. Interestingly, this regulated expression involves signalling through MEKl/extracellular regulating kinase (ERK), p38 mitogen activated protein kinase (MAPK), and p70 ${ }^{\mathrm{S} 6}$ kinase. $^{22}$

Different glycoconjugates on the surface of activated T cells appear to be primary receptors for galectins, including CD45, CD43, CD7, and CD2. ${ }^{23-25}$ In particular, CD7 has been identified as a critical receptor for galectin- 1 induced cell death, ${ }^{25}$ and it has been recently demonstrated that CD7 negative $T$ cells from patients with mycosis fungoides/Sézary syndrome are protected from galectin-1 triggered death. ${ }^{26}{ }^{27}$ Interestingly, galectin-1 binding to T cells results in a marked redistribution of receptors into segregated membrane microdomains. $^{23}$

The expression of $\mathrm{N}$-acetyllactosamine ligands by $\mathrm{T}$ cells, which may determine susceptibility to galectin- 1 induced cell death, is tightly controlled by specific glycosyltransferases, which are regulated during $\mathrm{T}$ cell development, activation, and differentiation. ${ }^{28}{ }^{29}$ Galvan and colleagues ${ }^{28}$ demonstrated that $\mathrm{CD} 45$ positive $\mathrm{T}$ cells lacking the core- $2-\beta-1,6-N$ acetylglucosaminyltransferase $(\mathrm{C} 2 \mathrm{GnT})$ are resistant to galectin-l induced cell death. This enzyme is responsible for creating branched structures on $O$-glycans of T cell surface glycoproteins, such as CD45. In addition, other glycosyltransferases can also act to reduce galectin binding to indirectly or directly masking galectin saccharide ligands. In this sense, addition of $\alpha 2,6$-linked sialic acids to lactosamine units by the ST6Gal-I sialyltransferase has been shown to block galectin-1 binding by interfering with lactosamine insertion into the binding pocket of galectin-1. ${ }^{29}$ Interestingly, recent findings suggest that altered glycosylation of T cells during human immunodeficiency virus (HIV)-1 infection increases their susceptibility to galectin-1 induced cell death, ${ }^{30}$ suggesting that this apoptotic pathway may contribute to HIV-1 induced immunosuppression.

The signal transduction events that lead to galectin-1 induced cell death include the induction of specific transcription factors (that is adaptor protein (AP)-1 and nuclear factor of activated T cells (NFAT)), ${ }^{16}{ }^{31}$ the modulation of Bcl-2 protein production, ${ }^{16}$ activation of caspases, ${ }^{17}$ modulation of the ceramide pathway, ${ }^{172}$ and release of cytochrome $c .{ }^{17}$ However, a recent study shows that apoptosis induced by galectin- 1 in a $\mathrm{T}$ cell line is not dependent on the activation of caspase-3 or on cytochrome $c$ release. ${ }^{18}$ Therefore, it seems evident that galectin-1 might trigger different death pathways or different apoptosis endpoints in different cell types.

In addition, however, using a human allogeneic $\mathrm{T}$ cell model we have recently demonstrated that alternative mechanisms may operate to achieve T cell immunosuppression including inhibition of proinflammatory cytokines in the non-apoptotic cell population. ${ }^{15}$ Moreover, there is recent evidence that exposure of activated leukocytes to dimeric galectin-1 may contribute to phagocytic recognition of these cells by inducing surface exposure of phosphatidylserine with no apparent signs of apoptosis. ${ }^{33}$ Most recently Endharti and colleagues $^{34}$ demonstrated that, in contrast to the proapoptotic role of galectin-1 on activated $\mathrm{T}$ cells, secretion of this protein by stromal cells is capable of supporting survival of naive $\mathrm{T}$ cells without promoting proliferation. ${ }^{34}$

Although these findings suggest a pivotal role for galectin1 in the establishment and maintenance of $\mathrm{T}$ cell tolerance and homoeostasis, targeted disruption of the galectin- 1 gene in knockout mice resulted in the absence of major spontaneous abnormalities, suggesting potential redundancy between different members of the galectin family. ${ }^{4}$ However, in contrast to these assumptions, recent work clearly indicates that galectin family members are not redundant and that there are subtle but functionally relevant differences in the specificity and function of individual members of the galectin family to regulate inflammatory responses (reviewed in reference 5).

\section{Galectin-2}

Galectin-2, a member of the galectin family structurally related to galectin- 1 has been also demonstrated to act as a proapoptotic protein. ${ }^{35}$ Investigation of the molecular mechanisms and intracellular pathways involved in the proapoptotic activity of this protein revealed binding to cell surface $\beta$-integrins but not to CD3 or CD7 receptors, involvement of caspase-3 and caspase-9, enhanced cytochrome $c$ release, disruption of the mitochondrial membrane potential and an increase of the Bax/Bcl-2 ratio. ${ }^{35}$ Studies of cytokine secretion by activated $\mathrm{T}$ cells incubated with galectin-2 revealed a significantly shift towards a $\mathrm{T}$ helper (Th) 2 profile. $^{35}$ These observations revealed substantial differences between galectin-2 and galectin-1 in terms of cell surface ligands and intracellular signalling pathways leading to cell death.

\section{Galectin-3}

Recent evidence indicates that galectin-3 could act in a dual manner either protecting cells from apoptosis or stimulating cell death depending on whether the protein is found in the intracellular compartment ${ }^{36}{ }^{37}$ or it acts extracellularly. ${ }^{38}$ Yang and colleagues ${ }^{36}$ demonstrated that $\mathrm{T}$ cell transfectants overexpressing galectin-3 display higher growth rates than control transfectants and are protected from apoptosis induced by a variety of agents including Fas ligation and staurosporine. ${ }^{36}$ Furthermore, the authors demonstrated that galectin-3 interacts with $\mathrm{Bcl}-2$ in a lactose dependent manner. ${ }^{36}$ Interestingly, Fukumori and colleagues ${ }^{38}$ demonstrated that secreted extracellular galectin-3 can signal apoptosis of human $\mathrm{T}$ cells. after binding to cell surface glycoconjugate receptors through carbohydrate dependent interactions. Analysis of the routes of signalling revealed that 
galectin-3 binds mainly to CD7 and CD29 ( $\beta 1$-integrins) resulting in activation of the mitochondrial pathway including cytochrome $c$ release and caspase-3, but not caspase-10 activation. ${ }^{38}$ Furthermore, recent evidence suggested a functional cross-talk between intracellular and extracellular galectins in the regulation of $\mathrm{T}$ cell death. ${ }^{18} \mathrm{Hahn}$ et $a l^{18}$ demonstrated that galectin-1-induced cell death is inhibited by intracellular expression of galectin-3. In addition, it has been recently demonstrated that galectin- 3 can act as a novel Fas-binding partner involved in the selection of different apoptotic signalling pathways. ${ }^{39}$ Finally, the antiapoptotic activity of galectin-3 has been directly or indirectly demonstrated in pathological situations including lymphomas, ${ }^{40}$ other types of cancer, ${ }^{41}$ and rheumatoid arthritis. ${ }^{42}{ }^{43}$

\section{Galectin-9}

Similarly to the proapoptotic role of galectin-1 in the thymic microenvironment, mouse galectin-9 also induces apoptosis of thymocytes in a lactose-inhibitable fashion. ${ }^{44}$ Furthermore, galectin-9 induces apoptosis of peripheral CD4+ and CD8+ T cells through a $\mathrm{Ca}^{2+}$-calpain-caspase-1 signalling pathway. ${ }^{45}$

\section{Other galectins: apoptosis on other cell types}

Although there is still no evidence regarding the role of other members of the galectin family in T cell death, it is becoming increasingly apparent that other galectins can regulate survival of many different cell types. For example, transfection of galectin-7 (p53-induced gene 1) in epithelial tumour cell lines revealed its intracellular proapoptotic activity. ${ }^{46}$ On the other hand, Arbel-Goren and colleagues ${ }^{47}$ revealed a major role for galectin-8 in the regulation of cell growth and apoptosis of tumour cell lines. Interestingly the authors found that cyclin dependent kinase inhibitors and jun kinase (c-Jun-N-terminal kinase (JNK)) can regulate the choice between growth arrest and apoptosis induced by galectin- $8 .{ }^{47}$ In addition, previous studies demonstrated that galectin- 12 expression regulates cell cycle progression ${ }^{48}$ and apoptosis of adipocytes. ${ }^{49}$ Thus, different members of the galectin family, can positively or negatively regulate survival of different cell types.

\section{Galectins as regulators of T cell activation and differentiation}

Immune cell activation and differentiation are key processes which determine the successful resolution of an inflammatory response following an antigenic challenge. In this context galectins have also been shown to influence different events associated with $\mathrm{T}$ cell activation and differentiation (see fig 1).

\section{Galectin- 1}

In addition to its role in the modulation of $\mathrm{T}$ cell survival, Vespa and colleagues ${ }^{50}$ demonstrated that galectin- 1 acts as a potent modulator of $\mathrm{T}$ cell receptor (TCR) signals and antagonises TCR induced interleukin (IL)-2 production in a murine $\mathrm{T}$ cell hybridoma clone. Interestingly, the same group further demonstrated that galectin- 1 induces partial TCR- $\zeta$ chain phosphorylation and is able to antagonise TCR responses known to require costimulation and processive protein tyrosine phosphorylation, such as IL-2 production, whereas it is permissive for TCR responses that only require partial TCR signals, such as CD69 upregulation and apoptosis. ${ }^{51}$ Thus, by acting at early events of TCR signalling, galectin-1 can also control $\mathrm{T}$ cell activation.

\section{Galectin-3}

Galectin-3 has been shown to positively contribute to cell interactions between dendritic cells and naive $\mathrm{T}$ cells in $\mathrm{T}$ cell dependent areas of lymph nodes. ${ }^{52}$ In contrast, Demetriou and colleagues ${ }^{53}$ reported that galectin-3 might play a role in restricting signal transduction initiated by TCR complexes. The authors hypothesised that galectin-3 might form multivalent complexes with $N$-glycans on the TCR, thereby restraining the lateral mobility of TCR complexes. ${ }^{53}$ This effect was abrogated in mice deficient in $\beta 1,6 \mathrm{~N}$-acetylglucosaminiltransferase (Mgat5), a crucial enzyme in the $N$ glycosylation pathway. These mice showed enhanced delayed-type hypersensitivity (DTH) responses and increased susceptibility to autoimmunity. ${ }^{53}$ Thus, galectin-3 may directly or indirectly influence $\mathrm{T}$ cell interactions with antigen presenting cells (APCs) and control $\mathrm{T}$ cell activation by regulating the immunological synapse. ${ }^{53}$

\section{Galectin-4}

Using a combined antigen-screening approach, Hokama and colleagues $^{54}$ found that galectin-4 plays a key role in CD4+ T cell activation under intestinal inflammatory conditions. ${ }^{54}$ Galectin-4-mediated stimulation of $\mathrm{T}$ cells was reflected by increase IL-6 production and was shown to exacerbate chronic colitis and delay recovery from acute intestinal injury. ${ }^{54}$

\section{Galectins as regulators of cytokine secretion}

The Th 1/Th 2 cytokine balance is crucial for determining the outcome of chronic inflammatory disorders and autoimmunity. It has been demonstrated that galectins can differentially regulate the cytokine balance in different inflammatory conditions (see fig 1).

\section{Galectin-1}

Galectin-1 has been shown to block secretion of proinflammatory cytokines in vitro, including IL-2, interferon $\gamma$ (IFN $\gamma$ ), and tumour necrosis factor $\alpha$ (TNF $\alpha) .^{51}{ }^{55}$ In addition in vivo studies in experimental models of chronic inflammation and autoimmunity showed the ability of galectin-1 to skew the balance towards a Th 2-type cytokine response, with decreased levels of IFN $\gamma$ and increased secretion of IL-5 or IL- 10 by pathogenic T cells. ${ }^{56-59}$ In the context of infection, we have demonstrated in an experimental model of Trypanosoma cruzi infection, that very low concentrations of galectin-1 (nanomolar range) are sufficient to downregulate the production of IL-12 and this effect correlated with an inhibitory effect on parasite replication without affecting cell viability. ${ }^{60}$ Furthermore, recent evidence indicates that, upon viral infection, galectin-1 can induce dendritic cell secretion of IL-6, a critical proinflammatory cytokine ${ }^{61}$ In addition, van der Leij and colleagues ${ }^{62}$ recently reported a marked increase in IL-10 mRNA and protein levels in non-activated and activated CD4+ and CD8+ T cells following treatment with recombinant galectin-1.62 Since IL-10 is known to suppress Th 1-type responses, upregulation of IL-10 may thus contribute to the immunoregulatory activity of galectin- 1 .

\section{Galectin-2}

Sturm and colleagues ${ }^{35}$ have demonstrated that galectin-2 can modulate $\mathrm{T}$ cell derived cytokines in vitro and shift the balance towards a Th 2 profile. ${ }^{35}$ In addition it has been shown that this protein can regulate lymphotoxin $\alpha$ secretion, which can in turn affect the degree of inflammation during myocardial infarction. ${ }^{63}$ Therefore, galectin-2, as well as galectin-1, can modulate the balance of proinflammatory and anti-inflammatory cytokines.

\section{Galectin-3}

Galectin-3 has been shown to act in most cases as a "proinflammatory cytokine", as has been clearly demonstrated by the attenuated inflammatory response in galectin3 knockout mice ${ }^{64}$ (and reviewed in reference 65). This has 
been also demonstrated by the reciprocal regulation of proinflammatory cytokines to regulate galectin-3 expression. $^{43}$ In addition, this lectin suppresses $\mathrm{T} \mathrm{h} 2$-mediated allergic inflammation by blocking IL-5 secretion by antigenspecific T cell lines. ${ }^{66}$ Furthermore, we have recently demonstrated that galectin-3 is a critical intracellular mediator of IL-4 induced survival and differentiation of $\mathrm{B}$ cells into a memory phenotype. ${ }^{67}$

\section{Galectin-4}

As described above, galectin- 4 has been recently shown to induce reactivity of intestinal $\mathrm{CD} 4+\mathrm{T}$ cells and exacerbate inflammation in intestinal tissue. ${ }^{54}$ Galectin-4 produced by epithelial cells induces IL-6 production by CD4+ T cells, an effect mediated by PKC $\theta$ associated pathways through the immunological synapse. ${ }^{54}$ Hence, galectin- 4 functions as a $\mathrm{T}$ cell activator by favoring secretion of proinflammatory cytokines.

Taken together, these data suggest, that under distinct physiological or pathological conditions, different members of the galectin family provide inhibitory or stimulatory signals to regulate immune cell homoeostasis and regulate inflammation following an antigenic challenge. Although the mechanisms of galectin mediated modulation of cytokine production are still obscure, we might hypothesise that different galectin family members trigger different signalling cascades to modulate the expression of different transcription factors involved in the regulation of cytokine synthesis.

\section{Other functions of galectins: regulations of innate immune responses}

In addition to their effects on $\mathrm{T}$ cell physiology, galectins have also been shown to influence the development of innate immune responses. ${ }^{68}$ We have demonstrated that galectin-1 suppresses the acute inflammatory response and inhibits neutrophil extravasation. ${ }^{69}$ Furthermore, this lectin suppresses arachidonic acid release and nitric oxide production from activated macrophages. ${ }^{69}{ }^{70}$ In addition, recent findings indicate that galectin-1 can inhibit neutrophil chemotaxis and transendothelial migration. ${ }^{71}$

In contrast to the anti-inflammatory effects of galectin-1 studies of acute peritonitis in mice deficient in galectin-3 provided significant support for the proinflammatory role of this lectin during acute inflammatory responses. ${ }^{64}{ }^{72}$ After intraperitoneal injection of thioglycolate, galectin-3 deficient mice had significantly reduced numbers of recoverable granulocytes compared with wild-type animals. ${ }^{64} 72$ Interestingly, however, Karlsson and colleagues ${ }^{73}$ showed $^{74}$ that both galectin-1 and galectin-3 are able to induce activation of the superoxide producing NADPH (nicotinamide adenosine dinucleotide phosphate (reduced form)) oxidase at similar levels in primed neutrophils. ${ }^{73}{ }^{74}$ Furthermore, regarding the role of galectins in cell-ECM interactions, galectin-3 has been shown to promote neutrophil adhesion to laminin ${ }^{75}$ and endothelial cells ${ }^{76}$ in vitro following an immunological challenge.

Recently, Liu and colleagues highlighted a critical role for galectin-3 in phagocytosis by macrophages. ${ }^{77}$ Compared with wild-type macrophages, galectin-3 deficient cells exhibited reduced phagocytic capacity. ${ }^{77}$ In addition, the same group showed that galectin-3 promotes chemotaxis of human monocytes through interaction with a G-protein coupled receptor ${ }^{78}$ and we have recently demonstrated that galectin-3 acts in concert with soluble fibrinogen to regulate neutrophil activation, degranulation, and survival through alternative MAPK pathways. ${ }^{79}$

Although not studied in detail as galectin-1 and galectin-3, other galectins also modulate innate immune responses. For example, galectin-8 can modulate neutrophil functions related to microbial killing. ${ }^{80}$ On the other hand, galectin-9 can act as an eosinophil specific $\mathrm{T}$ cell derived chemoattractant. ${ }^{81}$ Thus, galectins can act at different levels of the inflammatory cascade to regulate adaptive and innate immune responses.

\section{GALECTINS AS IMMUNOREGULATORS IN T CELL MEDIATED PATHOLOGY}

Failure of tolerance mechanisms may lead to autoreactive T cell activation and to induction of autoimmune diseases. To selectively interfere with the activation of pathogenic T cells involved in autoimmune disorders, ${ }^{82}$ immune intervention can be primarily directed to three cellular targets: APCs, autoreactive $\mathrm{T}$ cells, and suppressor/regulatory $\mathrm{T}$ cells. The common goal of these approaches is to selectively inhibit the activation, migration, and survival of pathogenic effector $\mathrm{T}$ cells. ${ }^{83}$ A growing body of experimental evidence indicates that galectins may play a role in the regulation of $\mathrm{T}$ cell mediated inflammatory disorders mainly by targeting pathogenic effector T cells. ${ }^{7}$ In this section we will summarise the clinical and immunological consequences of prophylactic or therapeutic administration of galectins (in particular galectin-1) in chronic inflammatory disorders and autoimmunity (table 1).

\section{Experimental autoimmune myasthenia gravis}

Myasthenia gravis is a relatively rare neurological disease that is associated with loss of the acetylcholine receptors that initiate muscle contraction. This results in muscle weakness, which can be life threatening. ${ }^{84}$ As early as 1983, Levi and colleagues $^{85}$ reported the prophylactic and therapeutic effects of electrolectin, an endogenous galectin from the fish Electrophorus electricus in experimental autoimmune myasthenia gravis (EAMG) induced by immunisation with purified acetylcholine receptors in rabbits. ${ }^{85}$ The administration of electrolectin to myasthenic rabbits led to clinical recovery; however this effect was not accompanied by any significant change in the level of circulating autoantibodies or modifications at the muscular level..$^{85}$ The authors suggested that electrolectin might play a role in the regulation of immune tolerance to self-antigens. However, at that time, the mechanisms involved in this process had not been investigated.

\section{Experimental autoimmune encephalomyelitis}

Experimental autoimmune encephalomyelitis (EAE) is considered as a model for multiple sclerosis and in both diseases Th 1-type cells specific for myelin antigen appear to play a critical pathogenic role. Offner and colleagues ${ }^{86}$ demonstrated that galectin-1 prevented the development of clinical and histopathological signs of EAE in Lewis rats. ${ }^{86}$ Although the mechanisms of action of the immunoregulatory activity of galectin-1 were not investigated in this study, the authors proposed that galectin-1 might block activation or sensitisation of encephalitogenic T cells. ${ }^{86}$ These pioneer studies in EAMG and EAE prompted us to investigate in vitro and in vivo the molecular mechanisms involved in the immunoregulatory activity of galectin-1.

\section{Collagen induced arthritis}

Rheumatoid arthritis (RA) is an immune mediated disease with a prominent involvement of Th 1 cells, characterised by articular inflammation and subsequent tissue damage leading to severe disability and increased mortality. ${ }^{87}$ Animal models of RA, such as collagen induced arthritis (CIA) have been essential in understanding the possible pathogenic mechanisms of this disease. We have demonstrated, using the DBA/l model, that a single injection syngeneic DAB/l fibroblasts engineered to secrete galectin- 1 at the day of onset 
Table 1 Immunoregulatory effects of administration of galectins (therapeutic and preventive) in experimental models of chronic inflammation, autoimmunity, and cancer

\begin{tabular}{|c|c|c|c|}
\hline Experimental models & Strategies used & Clinical outcome & Immunological outcome \\
\hline $\begin{array}{l}\text { Exogenous galectins } \\
\text { Experimental autoimmune myasthenia } \\
\text { gravis }\end{array}$ & Electrolectin administration & Clinical recovery & $\begin{array}{l}\text { No changes in circulating autoantibodies or } \\
\text { modifications at the muscular level }\end{array}$ \\
\hline $\begin{array}{l}\text { Experimental autoimmune encephalo- } \\
\text { myelitis (multiple sclerosis) }\end{array}$ & $\begin{array}{l}\text { Prophylactic administration } \\
\text { of galectin-1 }\end{array}$ & $\begin{array}{l}\text { Prevention of clinical and } \\
\text { histopathological manifestations }\end{array}$ & $\begin{array}{l}\text { Blockade of sensitisation of pathogenic T } \\
\text { cells }\end{array}$ \\
\hline $\begin{array}{l}\text { Collagen induced arthritis (rheumatoid } \\
\text { arthritis) }\end{array}$ & $\begin{array}{l}\text { Galectin-1 gene therapy } \\
\text { and protein administration }\end{array}$ & $\begin{array}{l}\text { Suppression of clinical and } \\
\text { histopathological manifestations }\end{array}$ & $\begin{array}{l}\text { Increased IL- } 5 \text { and decreased IFN } \gamma \\
\text { production } \\
\text { Increased T cell susceptibility to activation } \\
\text { induced cell death }\end{array}$ \\
\hline $\begin{array}{l}\text { Concanavalin } \mathrm{A} \text { induced hepatitis } \\
\text { (autoimmune hepatitis) }\end{array}$ & $\begin{array}{l}\text { Prophylactic administration } \\
\text { of galectin-1 }\end{array}$ & $\begin{array}{l}\text { Prevention of liver injury and } \\
\text { T helper cell liver infiltration }\end{array}$ & $\begin{array}{l}\text { Suppressed TNF } \alpha \text { and IFN } \gamma \text { production } \\
\text { Increased apoptosis of activated T cells }\end{array}$ \\
\hline $\begin{array}{l}\text { Inflammatory bowel disease } \\
\text { (experimental colitis) }\end{array}$ & $\begin{array}{l}\text { Prophylactic and therapeutic } \\
\text { administration } \\
\text { of galectin-1 }\end{array}$ & $\begin{array}{l}\text { Suppression of clinical and } \\
\text { histopathological manifestations }\end{array}$ & $\begin{array}{l}\text { Reduced ability of mucosal T cells to } \\
\text { produce IFN } \gamma \\
\text { Reduced proliferation of antigen specific T } \\
\text { cells } \\
\text { Increased number of apoptotic T cells within } \\
\text { mucosal tissue }\end{array}$ \\
\hline Nephrotoxic nephritis & $\begin{array}{l}\text { Galectin-1, galectin-3, and } \\
\text { galectin-9 administration }\end{array}$ & Clinical recovery & $\begin{array}{l}\text { Galectin-9 induces apoptosis of activated } \\
\text { CD8+ cells } \\
\text { Galectin-1 and galectin-3 block the } \\
\text { accumulation of macrophages in the renal } \\
\text { glomeruli }\end{array}$ \\
\hline Graft $v$ host disease & $\begin{array}{l}\text { Galectin-1 } \\
\text { administration }\end{array}$ & $\begin{array}{l}\text { Increased host survival following } \\
\text { allogeneic haematopoietic stem } \\
\text { cell transplantation }\end{array}$ & $\begin{array}{l}\text { Reduced production of IFNy and IL-2 } \\
\text { Reduced alloreactivity }\end{array}$ \\
\hline $\begin{array}{l}\text { Endogenous galectins } \\
\text { B16 melanoma }\end{array}$ & $\begin{array}{l}\text { Blockade of galectin-1 } \\
\text { expression in the tumour } \\
\text { microenvironment (galectin-1 } \\
\text { knockdown clones) }\end{array}$ & $\begin{array}{l}\text { Increased T cell mediated tumour } \\
\text { rejection }\end{array}$ & $\begin{array}{l}\text { Increased tumour specific IFN } \gamma \text { and IL-2 } \\
\text { production } \\
\text { Decreased number of infiltrating apoptotic } \mathrm{T} \\
\text { cells }\end{array}$ \\
\hline
\end{tabular}

of disease was able to abrogate clinical and histopathological manifestations of arthritis. ${ }^{56}$ Furthermore, investigation of the mechanisms involved in this process revealed a shift from a Th 1 to a Th 2-polarised immune response: this effect was manifested by reduced levels of IFN $\gamma$ and increased levels of IL-5 in draining lymph nodes from mice treated by gene or protein therapy with galectin- $1 .^{56}$ In addition, sera from treated mice showed reduced levels of anticollagen type II IgG2a antibodies and increased levels of anticollagen type II IgGl antibodies. Finally, the molecular bases of the therapeutic effect of galectin-1 were examined in vivo showing that lymph node cells from mice engaged in the galectin-1 gene therapy protocol had increased susceptibility to antigen induced apoptosis. Moreover, galectin-l expressing fibroblasts revealed an inhibitory effect in antigen-dependent IL-2 production to a collagen type II specific $\mathrm{T}$ cell hybridoma clone. ${ }^{56}$ This study provided a strong correlation between the apoptotic properties of galectin- 1 in vitro and its therapeutic potential in vivo. In addition, a strong correlation was found between the levels of galectin-1 and galectin-3 and the regulation of apoptosis in synovial tissue from patients with juvenile rheumatoid arthritis. ${ }^{42}$ On the other hand, Ohshima and colleagues ${ }^{43}$ found that galectin-3 is elevated in sera and synovial fluid from patients with RA. Interestingly, the authors found that RA synovial fibroblasts secrete high levels of galectin-3 into culture medium and that proinflammatory cytokines, such as TNF $\alpha$ markedly upregulate the intracellular content of galectin-3 in these cells. ${ }^{43}$ A brief outline of the potential role of galectin- 1 and galectin- 3 in the context of inflamed synovia is shown in fig 2 .

\section{Concanavalin A induced hepatitis}

Con A induced hepatitis represents a T cell dependent model of liver injury. Con A administration results in liver injury, leucocyte infiltration, increased transaminase plasma levels and hepatocyte apoptosis. ${ }^{88}$ Furthermore, Con A treatment leads to a marked increase in plasma TNF $\alpha$ and IFN $\gamma$ levels. Santucci and colleagues ${ }^{58}$ found that galectin-1 pretreatment prevented liver injury and Th cell liver infiltration induced by Con A. ${ }^{58}$ Using in vitro and in vivo experiments the authors demonstrated the protective effects of galectin-1 in this model and confirmed that galectin-1 acts in vivo by promoting selective elimination of antigen activated T cells. ${ }^{58}$ In addition, galectin-1 inhibited proinflammatory cytokine secretion from $\mathrm{T}$ cells and macrophages in a manner independent of its proapoptotic properties. ${ }^{58}$

\section{Inflammatory bowel disease}

Inflammatory bowel diseases (IBD), encompassing Crohn's disease (CD) and ulcerative colitis, are idiopathic chronic inflammatory conditions occurring with increasing frequency in Western populations. ${ }^{89}$ Although the etiology of IBD remains unknown, there is consistent evidence to link this condition to a failure of the mucosal immune system to attenuate the immune response to endogenous antigens. Support for this view has come from animal models of colitis, including the hapten model of colonic inflammation induced by intrarectal delivery of 2,4,6-trinitrobenzene sulphonic acid (TNBS), which consistently exhibits an excessive production of Th 1 derived cytokines. ${ }^{89}$ It has been demonstrated that prophylactic and therapeutic administration of galectin-1 


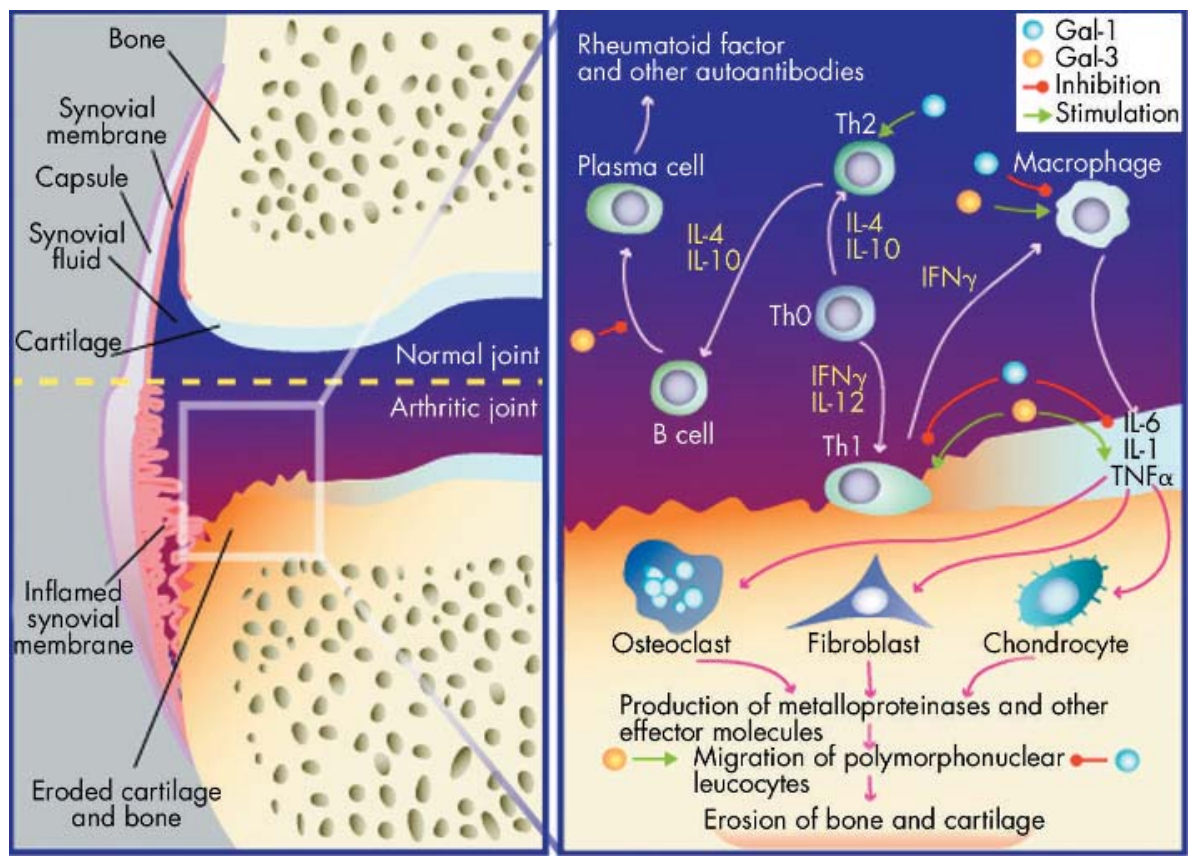

Figure 2 Galectins in immunopathology. Potential effects of galectin-1 (Gal-1) and galectin-3 (Gal3 ) in the context of inflamed synovial tissue in rheumatoid arthritis. IFN, interferon; IL, interleukin; TNF, tumour necrosis factor. results in striking improvement in the clinical and histopathological aspects of the disease. ${ }^{57}$ Furthermore, galectin- 1 treatment induced a reduction of the number of hapten activated spleen and mucosal $\mathrm{T}$ cells and decreased proinflammatory cytokine production. ${ }^{57}$ These results clearly indicated that galectin- 1 exerts protective and immunoregulatory activity in TNBS induced colitis and it also might be effective in the treatment of IBD.

\section{Nephrotoxic nephritis}

Nephrotoxic serum nephritis (NSN) represents a group of immune mediated disorders characterised by crescent formation and glomerular influx of CD8+ cells into glomerular capillaries. ${ }^{90}$ The disease can be induced in rats by injecting antiglomerular basement membrane serum. ${ }^{90}$ Tsuchiyama and colleagues ${ }^{90}$ investigated the efficacy of different members of the galectin family in the amelioration of $\mathrm{NSN}^{90}$ and found that galectin-9 induces apoptosis of activated CD8+ cells, while galectin- 1 and galectin- 3 block the accumulation of macrophages in the renal glomeruli. ${ }^{90}$ These findings raises the possibility to ameliorate immune mediated renal diseases by administration of galectins.

\section{Graft versus host disease}

Graft versus host disease (GVHD) is a lethal complication of allogeneic haematopoietic stem cell transplantation, where immunocompetent donor $\mathrm{T}$ cells attack the genetically disparate host cells. The predominant symptoms of acute graft versus host disease occur in the skin, liver, and intestine. ${ }^{91}$ Baum and colleagues ${ }^{59}$ investigated the efficacy of galectin- 1 in a murine model of graft versus host disease and found that $68 \%$ of mice treated with galectin- 1 survived, compared with $3 \%$ of vehicle -treated mice. Galectin-1 treatment reduced inflammatory infiltrates in affected tissues and significantly improved reconstitution of normal splenic architecture following transplantation. Similar to the findings in the CIA and IBD models, Th 1 cytokines were markedly reduced whereas production of Th 2 cytokines was similar between galectin-1 treated and control animals. ${ }^{59}$ These findings demonstrated that galectin-1 therapy is capable of suppressing graft versus host disease without compromising engraftment or immune reconstitution following allogeneic haematopoietic stem cell transplantation.

\section{Cancer: modulation of antitumour T cell mediated responses}

The immunoregulatory effects of galectin- $1^{1}$ and the correlation between galectin-1 expression in cancer cells and the aggressiveness of these tumours ${ }^{92}$ prompted us to investigate the role of galectin-l in tumour immune escape. We hypothesised that tumour cells may impair $\mathrm{T}$ cell effector functions through secretion of galectin-1 and that this mechanism may contribute in tilting the balance towards an immunosuppressive environment at the tumour site. By a combination of in vitro and in vivo experiments, we established a link between galectin-1-mediated immunoregulation and its contribution to tumour immune escape. ${ }^{20}$ Blockade of the inhibitory effects of galectin-1 within tumour tissue resulted in reduced tumour mass (an effect which required intact $\mathrm{CD} 4+$ and $\mathrm{CD} 8+\mathrm{T}$ cell responses) and stimulated the generation of a tumour specific $\mathrm{T}$ cell response in vivo..$^{20}$ Our observations supported the idea that galectin- 1 may contribute to immune privilege of tumours by modulating survival of effector $\mathrm{T}$ cells, and suggest a potential molecular target for manipulation of $\mathrm{T}$ cell tolerance and apoptosis with potential implications in immunotherapy.

\section{DISCUSSION AND FUTURE DIRECTIONS}

Recent advances in the understanding of the contribution of cell surface glycoconjugates and carbohydrate binding proteins to inflammatory processes have motivated the design of synthetic glycoconjugates or lectins as candidates for future generations of therapeutic drugs. ${ }^{93}{ }^{94}$ Galectins are involved in a variety of biological processes able to modulate immune responses including $\mathrm{T}$ cell survival, activation, differentiation, and cytokine secretion. In addition, the tolerogenic properties of galectins render these sugar binding proteins particularly suitable for the treatment of chronic inflammatory disorders and autoimmune diseases. In the present review we illustrated the relevance of different members of the galectin family in the regulation of $\mathrm{T}$ cell physiology and chronic inflammatory disorders. Despite considerable progress in elucidating galectin functions within 
the immune system, future comparative studies between different galectins will be necessary to address the precise role of individual members of the family and their functional redundancy, the toxicity of these proteins in vivo and the concentrations required to achieve different effects. The accumulating evidence for the multiple pleiotropic mechanisms regulated by galectins should indeed prompt further exploration of their potential in the development of therapies for several autoimmune disorders. In addition, given the influence of galectins in different events of tumour progression and metastasis, a current challenge is the design of specific and potent galectin inhibitors as potential anticancer agents.

\section{Authors' affiliations}

J M llarregui, G A Bianco, M A Toscano, G A Rabinovich, Division of Immunogenetics. Hospital de Clínicas "José de San Martín", Faculty of Medicine, University of Buenos Aires, Buenos Aires, Argentina

Work in authors' laboratory is supported by grants from Mizutani Foundation for Glycoscience (Japan), Agencia de Promoción Científica y Tecnológica (PICT 2003-05-13787), Fundación Antorchas (early career grant), Fundación Sales, Wellcome Trust (UK). and University of Buenos Aires (UBACYT-M091) to G A R.

Competing interests: none declared

Correspondence to: $\operatorname{Dr}$ G A Rabinovich, División Inmunogenética, Hospital de Clínicas "José de San Martín", Facultad de Medicina, Universidad de Buenos Aires, Av. Córdoba 2351. 3 Piso. (C1120) Ciudad de Buenos Aires, Argentina; gabyrabi@ciudad.com.ar

\section{REFERENCES}

1 Rabinovich GA, Baum LG, Tinari N, Paganelli R, Natoli C, Liu FT, et al. Galectins and their ligands: amplifiers, silencers or tuners of the inflammatory response. Trends Immunol 2002;23:313-20.

2 Rabinovich GA, Rubinstein N, Toscano M. Role of galectins in inflammatory and immunomodulatory processes. Biochim Biophys Acta 2002; 1572:274-84.

3 Cooper DNW. Galectinomics: Finding themes in complexity. Biochim Biophys Acta 2002;1572:209-31.

4 Leffler H, Carlsson S, Hedlund M, Qian Y, Poirier F. Introduction to galectins. Glycoconj J 2004; 19:433-40.

5 Liu FT, Rabinovich GA. Galectins as modulators of tumour progression. Nat Rev Cancer 2005;5:29-41.

6 Brewer CF. Binding and cross-linking properties of galectins. Biochim Biophys Acta 2002;1572:255-62.

7 Rubinstein N, llarregui JM, Toscano M, Rabinovich GA. The role of galectins in the initiation, amplification and resolution of the inflammatory response. Tissue Antigens 2004;64:1-12.

8 Liu FT, Patterson RJ, Wang JL. Intracellular functions of galectins. Biochim Biophys Acta 2002;1572:263-73.

9 Lenardo MJ. The molecular regulation of lymphocyte apoptosis. Semin Immunol 1997;9:1-15

10 Blaser C, Kaufmann M, Muller C, Zimmermann C, Wells V, Mallucci L, et al. $\beta$-galactoside-binding protein secreted by activated $T$ cells inhibits antigeninduced proliferation of T cells. Eur J Immunol 1998;28:231 1-19.

11 Perillo NL, Uittenbogaart CH, Nguyen JT, Baum LG. Galectin-1, an endogenous lectin produced by thymic epithelial cells, induces apoptosis of human thymocytes. J Exp Med 1997:97:1851-8.

12 Perillo NL, Pace KE, Seilhamer JJ, Baum LG. Apoptosis of T cells mediated by galectin-1. Nature 1995;378:736-39.

13 Rabinovich GA, Iglesias MM, Modesti NM, Castagna LF, Wolfenstein-Todel C, Riera CM, et al. Activated rat macrophages produce a galectin-1-like protein that induces apoptosis of T cells: Biochemical and functional characterization. $J$ Immunol 1998; 160:4831-40.

14 Zúñiga El, Rabinovich GA, Iglesias MM, Gruppi A. Regulated expression of galectin-1 during $B$ cell activation and implications for T-cell apoptosis $J$ Leukoc Biol 2001;70:73-9.

15 Rabinovich GA, Ramhorst RE, Rubinstein N, Corigliano A, Daroqui MC, KierJoffe EB, et al. Induction of allogeneic T -cell hyporesponsiveness by galectin1-mediated apoptotic and non-apoptotic mechanisms. Cell Death Diff 2002;9:661-70.

16 Rabinovich GA, Alonso CR, Sotomayor CE, Durand S, Bocco JL, Riera CM. Molecular mechanisms implicated in galectin-1-induced apoptosis: Activation of the AP-1 transcription factor and downregulation of Bcl-2. Cell Death Diff 2000;7:747-53.

17 Matarrese P, Tinari A, Mormone E, Bianco GA, Toscano MA, Ascione B, et al. Galectin-1 sensitizes resting human T lymphocytes to Fas (CD95)-mediated cell death via mitrochondrial hyperpolarization, budding and fission. J Biol Chem 2005;280:6969-85
18 Hahn HP, Pang M, He J, Hernandez JD, Yang RY, Li LY, et al. Galectin-1 induces nuclear translocation of endonuclease $G$ in caspase- and cytochrome c-independent T cell death. Cell Death Diff 2004;11:1277-86.

19 Rabinovich GA, Modesti NM, Castagna LF, Landa CA, Riera CM, Sotomayor CE. Specific inhibition of lymphocyte proliferation and induction of apoptosis by CLL-1, a beta-galactoside-binding lectin. J Biochem 1997; 122:365-73.

20 Rubinstein N, Alvarez M, Zwirner NW, Toscano MA, llarregui JM, Bravo A, et al. Targeted inhibition of galectin-1 gene expression in tumor cells results in heightened T cell-mediated rejection: A potential mechanism of tumor-immune privilege. Cancer Cell 2004;5:241-51.

21 He J, Baum LG. Presentation of galectin-1 by extracellular matrix triggers Tcell death. J Biol Chem 2004;279:4705-12.

22 Fuertes MB, Molinero LL, Toscano MA, llarregui JM, Rubinstein N, Fainboim L, et al. Regulated expression of galectin-1 during T-cell activation involves Lck and Fyn kinases and signaling through MEK1/ERK, p38 MAP kinase and p70 56 kinase. Mol Cell Biochem 2004;267:177-85.

23 Pace KE, Lee C, Stewart PL, Baum LG. Restricted receptor segregation into membrane microdomains occurs on human T cells during apoptosis induced by galectin-1. J Immunol 1999;163:3801-11

24 Walzel H, Blach M, Hirabayashi J, Kasai KI, Brock J. Involvement of CD2 and CD3 in galectin-1 induced signaling in human Jurkat T-cells. Glycobiology 2000;10:131-40

25 Pace KE, Hahn HP, Pang M, Nguyen JT, Baum LG. CD7 delivers a proapoptotic signal during galectin-1-induced T cell death. J Immunol 2000; 165:2331-4

26 Rappl G, Abken H, Muche JM, Sterry W, Tilgen W, Andre S, et al. CD4 ${ }^{+}$CD7$T$ cells from patients with Sezary syndrome are protected from galectin-1triggered T cell death. Leukemia 2002;16:840-5.

27 Roberts AA, Amano M, Felten C, Galvan M, Sulur G, Pinter-Brown L, et al. Galectin-1-mediated apoptosis in mycosis fungoides: the role of CD7 and cell surface glycosylation. Mod Pathol 2003;16:543-51.

28 Galvan M, Tsuboi S, Fukuda M, Baum LG. Expression of a specific glycosyltransferase enzyme regulates T-cell death mediated by galectin-1. J Biol Chem 2000;275:16730-7.

29 Amano M, Galvan M, He J, Baum LG. The ST6Gal I sialyltransferase selectively modifies $\mathrm{N}$-glycans on CD45 to negatively regulate galectin-1induced CD45 clustering, phosphatase modulation and T cell death. J Biol Chem 2003;278:7469-75

30 Lanteri M, Giordanengo V, Hiraoka N, Fuzibet JG, Auberger P, Fukuda M, et al. Altered T cell surface glycosylation in HIV-1 infection results in increased susceptibility to galectin-1-induced cell death. Glycobiology 2003;13:909-18.

31 Walzel H, Blach M, Hirabayashi J, Arata Y, Kasai K, Brock J. Galectininduced activation of the transcription factors NFAT and AP-1 in human Jurkat T-lymphocytes. Cell Signal 2002;14:861-68.

32 Ion G, Fajka-Boja R, Toth GK, Caron M, Monostori E. Role of p56(lck) and ZAP70-mediated tyrosine phosphorylation in galectin-1-induced cell death. Cell Death Diff 2005;12:1145-7.

33 Dias-Baruffi M, Zhu H, Cho M, Karmakar S, McEver RP, Cummings RD. Dimeric galectin-1 induces surface exposure of phosphatidylserine and phagocytic recognition of leukocytes without inducing apoptosis. J Biol Chem 2003;278:41282-93.

34 Endharti AT, Zhou YW, Nakashima I, Suzuki H. Galectin-1 supports survival of naive T cells without promoting cell proliferation. Eur J Immunol 2005;35:86-97.

35 Sturm A, Lensch M, Andre S, Kaltner H, Wiedenmann B, Rosewicz S, et al. Human galectin-2: novel inducer of $T$ cell apoptosis with distinct profile of caspase activation. J Immunol 2004;173:3825-37.

36 Yang RY, Hsu DK, Liu FT. Expression of galectin-3 modulates T cell growth and apoptosis. Proc Natl Acad Sci U S A 1996;93:6737-42.

37 Akahani S, Nangia-Makker P, Inohara H, Kim HR, Raz A. Galectin-3: a novel antiapoptotic molecule with a functional BHI (NWGR) domain of $\mathrm{Bcl}-2$ family. Cancer Res 1997:57:5272-6.

38 Fukumori T, Takenaka Y, Yoshii T, Kim HR, Hogan V, Inohara H, et al. CD29 and CD7 mediate galectin-3-induced type II T-cell apoptosis. Cancer Res 2003;63:8302-11.

39 Fukumori T, Takenaka Y, Oka N, Yoshii T, Hogan V, Inohara H, et al. Endogenous galectin-3 determines the routing of CD95 apoptotic signaling pathways. Cancer Res 2004;64:3376-79.

40 Hoyer KK, Pang M, Gui D, Shintaku IP, Kuwabara I, Liu FT, et al. An antiapoptotic role for galectin-3 in diffuse large B-cell lymphomas. Am J Pathol 2004; 164:893-902.

41 Nakahara S, Oka N, Raz A. On the role of galectin-3 in cancer apoptosis Apoptosis 2005; 10:267-75

42 Harjacek M, Diaz-Cano S, de Miguel M, Wolfe H, Maldonado CA, Rabinovich GA. Expression of galectins -1 and -3 correlates with defective mononuclear cell apoptosis in patients with juvenile idiopathic arthritis. $J$ Rheumatol 2001;28:1914-22.

43 Ohshima S, Kuchen S, Seemayer CA, Kyburz D, Hirt A, Klinzing S, et al Galectin-3 and its binding protein in rheumatoid arthritis. Arthritis Rheum 2003:48:2788-95

44 Wada J, Ota K, Kumar A, Wallner El, Kanwar YS. Developmental regulation, expression, and apoptotic potential of galectin-9, a beta-galactoside-binding lectin. J Clin Invest 1997;99:2452-61.

45 Kashio Y, Nakamura K, Abedin MJ, Seki M, Nishi N, Yoshida N, et al. Galectin-9 induces apoptosis through the calcium-calpain-caspase 1 pathway. J Immunol 2003;170:3631-6.

46 Kuwabara I, Kuwabara Y, Yang RY, Schuler M, Green DR, Zuraw BL, et al. Galectin-7 (PIG1) exhibits pro-apoptotic function through JNK activation and mitochondrial cytochrome $c$ release. J Biol Chem 2002;277:3487-97. 
47 Arbel-Goren R, Levy Y, Ronen D, Zick Y. Cyclin-dependent kinase and JNK act as molecular switches, regulating the choice between growth arrest and apoptosis induced by galectin-8. J Biol Chem 2005;280:19105-14.

48 Yang RY, Hsu DK, Yu L, Ni J, Liu FT. Cell cycle regulation by galectin-12, a new member of the galectin superfamily. J Biol Chem 2001;276:20252-60.

49 Hotta K, Funahashi T, Matsukawa Y, Takahashi M, Nishizawa H, Kishida K, et al. Galectin-12, an adipose-expressed galectin-like molecule possessing apoptosis-inducing activity. J Biol Chem 2001;276:34089-97.

50 Vespa GN, Lewis LA, Kozak KR, Moran M, Nguyen JT, Baum LG, et al. Galectin-1 specifically modulates TCR signals to enhance TCR apoptosis but inhibits IL-2 production and proliferation. J Immunol 1999;162:799-806.

51 Chung CD, Patel VP, Moran M, Lewis LA, Miceli MC. Galectin-1 induces partial TCR $\zeta$-chain phosphorylation and antagonizes processive TCR signal transduction. J Immunol 2000:165:3722-9.

52 Swarte VV, Mebius RE, Joziasse DH, Van den Eijnden DH, Kraal G. Lymphocyte triggering via L-selectin leads to enhanced galectin-3-mediated binding to dendritic cells. Eur J Immunol 1998;28:2846-71.

53 Demetriou M, Granovsky M, Quaggin S, Dennis JW. Negative regulation of T-cell activation and autoimmunity by Mgat5 $\mathrm{N}$-glycosylation. Nature 2001;409:733-9.

54 Hokama A, Mizoguchi E, Sugimoto K, Shimomura Y, Tanaka Y, Yoshida M et al. Induced reactivity of intestinal $\mathrm{CD} 4^{+} \mathrm{T}$ cells with an epithelial cell lectin galectin-4, contributes to exacerbation of intestinal inflammation. Immunity 2004; 20:681-93.

55 Rabinovich GA, Ariel A, Hershkoviz R, Hirabayashi J, Kasai KI, Lider O. Specific inhibition of T-cell adhesion to extracellular matrix and proinflammatory cytokine secretion by human recombinant galectin-1. Immunology 1999:97:100-6.

56 Rabinovich GA, Daly G, Dreja H, Tailor H, Riera CM, Hirabayashi J, et al. Recombinant galectin-1 and its genetic delivery suppress collagen-induced arthritis via T cell apoptosis. J Exp Med 1999;190:385-97.

57 Santucci L, Fiorucci S, Rubinstein N, Mencarelli A, Palazzetti B, Federici B, et al. Galectin-1 suppresses experimental colitis in mice. Gastroenterology 2003; 124:1381-94.

58 Santucci L, Fiorucci S, Cammilleri F, Mencarelli A, Palazzetti B, Federici B, et al. Galectin-1 exerts immunomodulatory and protective effects on concanavalin A-induced hepatitis in mice. Hepatology 2000;31:399-406.

59 Baum LG, Blackall DP, Arias-Magallano S, Nanigian D, Uh SY, Browne JM, et al. Amelioration of graft versus host disease by galectin-1. Clin Immunol 2003; 109:295-307

60 Zuñiga El, Gruppi A, Hirabayashi J, Kasai KI, Rabinovich GA. Regulated expression and effect of galectin-1 on Trypanosoma cruzi-infected macrophages: Modulation of microbicidal activity and survival. Infect Immun 2001;69:6804-12.

61 Levroney EL, Aguilar HC, Fulcher JA, Kohatsu L, Pace KE, Pang M, et al. Novel innate immune functions for galectin-1: galectin-1 inhibits cell fusion by nipah virus envelope glycoproteins and augments dendritic cell secretion of proinflammatory cytokines. J Immunol 2005;175:413-20.

62 van der Leij J, van den Berg A, Blokziil T, Harms G, van Goor H, Zwiers P, et al. Dimeric galectin-1 induces IL-10 production in T-lymphocytes: an important tool in the regulation of the immune response. J Pathol 2004:204:51 1-18.

63 Ozaki K, Inove K, Sato H, lida A, Ohnishi Y, Sekine A, et al. Functional variation in LGALS2 confers risk of myocardial infarction and regulates lymphotoxin-alpha secretion in vitro. Nature 2004;429:72-5.

64 Hsu DK, Yang RY, Yu L, Yu L, Salomon DR, Fung-Leung WP, et al. Targeted disruption of galectin-3 gene results in attenuated peritoneal inflammatory responses. Am J Pathol 2000;156:1073-83.

65 Liu FT. Regulatory roles of galectins in the immune response. Int Arch Allergy Immunol 2005;136:385-400.

66 Cortegano I, del Pozo V, Cardaba B, de Andres B, Gallardo S, del Amo A, et al. Galectin-3 down-regulates IL-5 gene expression on different cell types. $\mathrm{J}$ Immunol 1998;161:385-9.

67 Acosta-Rodríguez EV, Montes CL, Motran CC, Zuniga El, Liu FT Rabinovich GA, et al. Galectin-3 mediates interleukin-4-induced survival and differentiation of $B$ cells. Functional cross-talk and implications during Trypanosoma cruzi infection. J Immunol 2004;172:493-502.

68 Rabinovich GA, Toscano MA, llarregui JM, Rubinstein N. Shedding light on the immunomodulatory properties of galectins: Novel regulators of innate and adaptive immune responses. Glycoconj J 2004; 19:565-73.

69 Rabinovich GA, Sotomayor CE, Riera CM, Bianco I, Correa SG. Evidence of a role for galectin-1 in acute inflammation. Eur J Immunol 2000;30:1331-9.
70 Correa SG, Sotomayor CE, Aoki MP, Maldonado CA, Rabinovich GA. Opposite effects of galectin-1 on alternative metabolic pathways of $L$-arginine in resident, inflammatory and activated macrophages. Glycobiology 2003;13:119-28.

71 La M, Cao TV, Cerchiaro G, Chilton K, Hirabayashi J, Kasai K, et al. A novel biological activity for galectin-1: inhibition of leukocyte-endothelial cell interactions in experimental inflammation. Am J Pathol 2003;63:1505-15.

72 Colnot C, Ripoche MA, Milon G, Montagutelli X, Crocker PR, Poirier F. Maintenance of granulocyte numbers during acute peritonitis is defective in galectin-3-null mutant mice. Immunology 1998;94:290-6.

73 Karlsson A, Follin P, Leffler H, Dahlgren C. Galectin-3 activates the NADPH oxidase in exudated but not peripheral blood neutrophils. Blood 1998;91:3430-8

74 Almkvist J, Dahlgren C, Leffler H, Karlsson A. Activation of the neutrophil nicotinamide adenine dinucleotide phosphatase oxidase by galectin-1. $\mathrm{J}$ Immunol 2002;168:4034-41.

75 Kuwabara I, Liu FT. Galectin-3 promotes adhesion of human neutrophils to laminin. J Immunol 1996; 156:3939-44.

76 Sato S, Ouellet N, Pelletier I, Simard M, Rancourt A, Bergeron MG. Role of galectin-3 as an adhesion molecule for neutrophil extravasation during streptococcal pneumonia. J Immunol 2002;168:1813-22.

77 Sano H, Hsu DK, Apgar JR, Yu L, Sharma BB, Kuwabara I, et al. Critical role of galectin-3 in phagocytosis by macrophages. J Clin Invest 2003;112:389-97.

78 Sano H, Hsu DK, Yu L, Apgar JR, Kuwabara I, Yamanaka T, et al. Human galectin-3 is a novel chemoattractant for monocytes and macrophages. $\mathrm{J}$ Immunol 2000;165:2156-64.

79 Fernández GC, Ilarregui JM, Rubel CJ, Toscano MA, Gomez SA, Beigier Bompadre $M$, et al. Galectin-3 and soluble fibrinogen act in concert to modulate neutrophil activation and survival. Involvement of alternative MAPK pathways. Glycobiology 2005;15:519-27.

80 Nishi N, Shoji H, Seki M, Itoh A, Miyanaka H, Yuube K, et al. Galectin-8 modulates neutrophil function via interaction with integrin alphaM. Glycobiology 2003;13:755-63.

81 Matsumoto R, Hirashima M, Kita H, Gleich GJ. Biological activities of ecalectin: a novel eosinophil-activating factor. J Immunol 2002; 168:1961-67.

82 Feldmann $M$, Steinman L. Design of effective immunotherapy for human autoimmunity. Nature 2005;435:612-19.

83 Adorini L. Selective immunointervention in autoimmune diseases: lessons from multiple sclerosis. J Chemother 2001;13:219-34.

84 Vincent A. Unravelling the pathogenesis of myasthenia gravis. Nat Rev Immunol 2002;2:797-804.

85 Levi G, Tarrab-Hazadai R, Teichberg VI. Prevention and therapy with electrolectin of experimental autoimmune myasthenia gravis in rabbits. Eur J Immunol 1983;13:500-7

86 Offner H, Celnik B, Bringman TS, Casentini-Borocz D, Nedwin GE, Vandenbark AA. Recombinant human beta-galactoside binding lectin suppresses clinical and histological signs of experimental autoimmune encephalomyelitis. J Neuroimmunol 1990;28:177-84.

87 Breedveld FC. Multiple faces of rheumatoid arthritis: diagnostic and therapeutic algorithsms. Autoimmun Rev 2004;3:S22.

88 Tsutsui H, Adachi K, Seki E, Nakanishi K. Cytokine-induced inflammatory liver injuries. Curr Mol Med 2003;3:545-59.

89 Gordon JN, Sabatino AD, Macdonald TT. The pathophysiologic rationale for biological therapies in inflammatory bowel disease. Curr Opin Gastroenterol 2005;21:431-7.

90 Tsuchiyama Y, Wada J, Zhang H, Morita Y, Hiragushi K, Hida K, et al. Efficacy of galectins in the amelioration of nephrotoxic serum nephritis in Wistar Kyoto rats. Kidney Int 2000;58:1941-52.

91 Iwasaki T. Recent advances in the treatment of graft-versus-host disease. Clin Med Res 2004;2:243-52.

92 Danguy A, Camby I, Kiss R. Galectins and cancer. Biochem Biophys Acta 2002;1572:285-93.

93 Dube DH, Bertozzi CR. Glycans in cancer and inflammation. Potential for therapeutics and diagnostics. Nat Rev Drug Discov 2005;4:477-88.

94 Blixt O, Head S, Mondala T, Scanlan C, Huflejt ME, Alvarez R, et al. Printed covalent glycan array for ligand profiling of diverse glycan-binding proteins. Proc Natl Acad Sci U S A 2004;101:17933-8. 